\title{
Investigating the role of customer churn in the optimal allocation of offensive and defensive advertising: the case of the competitive growing market $^{1}$
}

\section{Dominika Machowska}

\begin{abstract}
The paper investigates the optimal allocation between defensive and offensive advertising efforts in a dynamic, growing market in which two companies are competing for market share. The study described in this paper extends the existing literature on dynamic advertising competition by considering a market that is in the growth phase and by including the heterogeneous decay rate of market share. A modified Lanchester is employed to describe the dynamics of market share by model. The goal of companies operating in this domain is to maximize their profits over a finite decision horizon. Based on the differential game approach the Markovian Nash strategies for offensive and defensive advertising activities are determined. Additionally, an analysis of the extent to which this solution is sensitive to changes in potential market and the rate of customer churn is made.
\end{abstract}

Keywords: Lanchester model, Markovian Nash equilibrium, defensive and offensive advertising, potential market, customer churn.

JEL codes: C61, C72, D43, M37.

\section{Introduction}

Customer churn ${ }^{3}$ occurs when customers switch from one company to another or leave a given market altogether (Libai, Muller, \& Peres, 2009). Empirical investigations have shown that the loss of customers can lead to substantial economic losses (Ahn, Han, \& Lee, 2006; KhakAbi, Gholamian, \& Namvar, 2010). Previous studies have proven that the development of a strong relationship between organisations and customers generates a long-term profit (Hamilton, Rust, \& Dev, 2017); as such managers and scientists have turned their atten-

\footnotetext{
${ }^{1}$ Article received: 7 August 2017, accepted 30 March 2018.

${ }^{2}$ University of Lodz, Faculty of Economics and Sociology, Department of Econometrics, POW 3/5, 90-255 Łódź, dominika.machowska@uni.lodz.pl.

${ }^{3}$ In the literature customer churn rate is also known as the decay rate, attrition rate or defection rate. Therefore, in this paper all these terms are used interchangeably.
} 
tion to customer attrition (and its complement, customer retention). Neslin, Gupta, Kamakura, Lu and Mason (2006) highlighted how the management of customer defection represents a considerable challenge for many companies in different sectors such as publishing, banking, financial services, insurance and mobile phone service providers. Libai et al. (2009) observed that insufficient attention has been devoted to modelling and analysing the effect that attrition has on strategic marketing decisions.

Customer attrition is of the most significance when it comes to durable products or services because customer acquisition within this segment is very expensive (Rust \& Chung, 2006). Retaining consumers can be extremely beneficial for an organisation. To this end, the research described in this paper placed a particular emphasis on the competitive market for durable products.

The aim of the study was to develop a framework which enables an understanding as to how the dynamics of customer attrition affect offensive and defensive marketing strategies in a growing competitive market. Reinartz and Venkatesan (2008) highlighted how managers need tools by which they can control various types of advertising strategies, take into account the dynamics of the market and react to the actions of competitors. Furthermore, Rust and Chung (2006) analysed the needs related to the introduction of CRM ideology, emphasising how practitioners require viable models by which they can optimally manage advertising strategies that take different decision horizons into account. However, Min, Zhang, Kim and Srivastava (2016) stressed how undertaking strategic marketing decisions about the allocation of resources between acquisition and retention in a growing market represents a significant challenge.

To address the needs described above the aim of this study was to employ a differential game approach to construct a tool that proves to be indispensable for analysing dynamic advertising efforts in a competitive environment (Fruchter, 1999). To facilitate this process the Lanchester model, which is universally used to describe many conflictual situations in oligopolistic markets, was used. The general idea is to describe the dynamics of the competition that result from each company's advertising efforts to attract the rivals' market share and capture the biggest share of the potential market. A summary of the existing models that describe advertising competition is presented in Section 2.

In this paper a dynamic model through which it is possible to determine the optimal (in the sense of profit-maximising) allocation between defensive and offensive advertising efforts in a competitive market of potential customers is presented. Through the use of offensive advertising organisations can acquire new customers who switch from a competitor or attract new customers to the segment. The organisation can also invest in defensive actions that hinder a rival's advertising action. The firm can lose customers who subsequently become part of the potential market. The new model is defined on a finite decision horizon. This makes it possible to take a time-varying churn rate and other model parameters into consideration. For the model formulated for the differential 
game the Markovian Nash equilibria were identified. This allows the identification of the optimal strategies for all companies in the sense that any company is not able to achieve a more significant profit through the individual modification of its policy. In contrast to an open-loop equilibrium Markovian Nash advertising strategies are dependent on the current state of the system (i.e., on the current saturated market shares of both companies) and, due to the finite horizon, they are time-varying. This type of equilibrium is close to economic reality because it allows managers to revise advertising strategies in the light of market changes. This observation has been empirically confirmed by Erickson (1992) and more recently by Wang and Wu (2001).

The impact of churn in the Lanchester model was analysed in a study by Prasad, Sethi and Naik (2012). The authors considered optimal offensive advertising decisions over an infinite horizon. They recognised that this type of advertising decreases as the churn rate increases. However in this paper the study is expanded to include the decay rate. From Hamiltonian maximisation conditions a system of differential equations with initial and terminal conditions (so-called boundary valued problem) that do not possess an analytical solution were obtained thus making the solution numeric. In this way the tool to conduct a sensitivity analysis of the optimal solution was obtained. Several examples of the modified Lanchester model were examined to discover how the attrition rate influences offensive and defensive advertising and company profit. Attention is drawn to the differences in Nash equilibria of both advertising activities between a growing and mature market for various levels of decay rate. The focus is on the optimal advertising strategies for time-varying churn rate.

The remainder of the paper is structured as follows. Section 1 formulates the research hypotheses. Section 2 reviews the existing literature that has modelled advertising competition. Section 3 presents the modified Lanchester model. A mathematical formulation of the potential market and its properties are also analysed. Section 4 establishes the Markovian Nash equilibria. Section 5 presents the sensitivity analysis of the optimal solutions. A conclusion closes the paper.

\section{Theory and hypotheses}

In this section the relevant literature to formulate hypotheses about the correlation between customer attrition, company profit, and optimal advertising strategies is examined and the extent to which the existence and size of the potential market influence these relationships.

\section{The potential market}

Kotler and Armstrong (2017) distinguished between four significant phases of market evolution: emergence, growth, maturity and decline. This paper focusses on the growth phase, which is characterised by the existence of a so-called 
potential market. This segment of the market consists of potential customers who are not customers of any company that is currently operating within the market; however, there is a chance these customers will choose a competitor. Many empirical studies have confirmed the essential and unique role of the growing market. The analysis of econometric models confirms that different phases of market evolution may directly impact on how consumers react to advertising or the interaction between competitive dynamics (Dekimpe \& Hanssens, 1995; Chandy, Tellis, MacInnis, \& Thaivanich, 2001). Agarwal and Bayus (2002) recognised that strategic decisions made within a growing market environment have a significant long-term impact on market positions and the overall profitability of the organisations that are competing in that market. The following hypotheses were created:

$\mathbf{H}_{\mathbf{1}}$ : There is a positive relationship between the size of the potential market and company profit.

\section{Customer churn}

Customer churn includes different aspects of abandoning the product. It captures the exogenous influences that may mean that a consumer stops purchasing a given product, such as the age at which the consumer no longer uses or needs the product or service and/or ideological reasons; e.g. the consumer ceases to use a car because of air pollution. A further aspect that impacts customer churn is a discrepancy between the quality or attributes of a product and consumer expectations. Reinartz and Venkatesan (2008) described two types of behaviour in the context of customer attrition: 'lost-for-good' and 'migration.' The first category contains customers who stop buying the product or terminate their relationship with a service provider on a permanent basis. They do not expect to return in the future. The second type is customers who stop buying the product for a limited time but may commence purchasing it again in the future (Rust, Lemon, \& Zeithaml, 2004). Hogan, Lemon and Libai (2003) claimed that 'migration' better reflects economic reality. They stated that longitudinal improvement of products or services may attract customers who were previously dissatisfied. Reichheld and Sasser (1990) emphasised that the decay rate adversely affects companies by decreasing profit and losing a great deal of price premium. Thus:

$\mathbf{H}_{2}$ : The churn rate decreases company profit.

However an increase in customer attrition increases the size of the potential customer market because dissatisfied customers leave the company and, therefore, become a part of the potential market. Ahn et al. (2006) recognised that customer churn becomes a severe problem in a mature market in which the competition is very strong. Therefore it is possible to postulate that: 
$\mathbf{H}_{3}$ : The size of the potential market moderates the extent to which the customer churn rate impacts advertising strategies.

The assumption that the attrition rate is constant over time seems unlikely to be accurate. The time-varying dynamics may reflect a change in the perceived quality of the product in the decision horizon, which is a particularly important assumption for the growing market. At this stage companies are work continually to tailor the product to consumer expectations. There may also be exogenous changes in purchasing preferences among consumers, especially in a mature market. A declining churn rate means that the number of customers leaving the company decreases and this reflects a situation in which customers notice more and more positive features of the product or service. It can also mean that exogenous factors such as changes in fashions, affect consumers' interests in the product. This leads to the following:

$\mathbf{H}_{4}$ : A reduction in churn rate increases company profit.

\section{Offensive advertising}

An offensive advertising campaign is focused on acquiring new customers for a company and, therefore, increasing the company's market share (Davidson \& Keegan, 2004). In a mature market, offensive strategies are usually targeted at a rival company's customers (Martín-Herrán, McQuitty, \& Sigué, 2012). However when operating in a growing market it is essential that organisations acquire potential customers who are new to the market (Kotler \& Armstrong, 2017). Organizations that operate at different stages of the market lifecycle will ultimately lose customers at some point. As such every company recognises the need to replace attrition.

On the one hand the growth of customer attrition may result in a decline in offensive advertising efforts because customers leave the organisation quickly and do not generate long-term profit. On the other hand the growth in the decay rate may force the company to rebuild its customer base and this may mean that it increases its offensive efforts. However, from the maximisation point of view, an increase in the decay rate results in a decline in offensive advertising efforts (Prasad et al., 2012). This leads to the following:

$\mathbf{H}_{5}:$ There is an inverse relationship between customer churn and offensive advertising.

In the event that the attrition rate declines as time goes by it is expected that the company will increase its offensive advertising spending in comparison to a situation in which the decay is consistent. Therefore:

$\mathbf{H}_{6}:$ A decreasing churn rate increases offensive advertising. 


\section{Defensive advertising}

Defensive strategies belong to post-purchase activities and involve communicating with existing customers. They focus on retaining the company's current customers by increasing customer satisfaction and building long-term positive relationships. Thus the primary difference between offensive and defensive advertising strategies is the target group of customers. Furthermore they also differ in terms of the marketing tools employed. Hamilton et al. (2017) conducted an empirical study on the hotel service industry through which they confirmed that different marketing activities influence customer attraction and different actions have an impact on retention. Defensive strategies may also be employed to neutralise the offensive efforts of the competitor. It is this aspect of defensive efforts that are included in the new model of advertising competition. Therefore:

$\mathbf{H}_{7}$ : The customer churn rate is negatively associated with defensive advertising.

$\mathbf{H}_{\mathbf{8}}:$ A reduction in the churn rate decreases defensive advertising.

\section{A dynamic model of advertising competition}

The dynamic advertising literature contains a large number of differential-game based models that may be divided into three groups for the purposes of the literature review presented in this paper.

\section{The Lanchester models}

The first group of differential-game based models includes those models that are derived from the Lanchester approach. Each competitor uses advertising as a primary tool to control its market position and increase profit and the company expands its market share through offensive advertising activities that are directed at a rival's customers. At the same time the market share is reduced as a result of the advertising actions of the competitors. Without any advertising, the market share of each company remains unchanged. Finally the market is considered to be mature; i.e. the market size is constant, and the sum of the market shares of all players is equal to 1 (Jørgensen \& Zaccour, 2012). The research of Chintagunta and Vilcassim (1992), Fruchter and Kalish (1997), Jarrar, Martín-Herrán and Zaccour (2004), Nguyen and Shi (2006) all belong to this category.

There is a need for advertising competition research in the growing market (Min et al., 2016). However this point has been examined in only in a few papers. As described in Section 1, this type of market is characterised by the existence of the potential market. Fruchter (1999) was the first to observe how the 
assumption of a constant market size represents a serious limitation because it is not aligned with economic reality. Therefore she modified the Lanchester approach by assuming that the market share of each player increases in response to offensive advertising activities that are directed at the rival's customers and the potential customers in the untapped part of the market (see also Wang \& Wu, 2001).

Recently the literature on relationship marketing has highlighted the important role customer retention activities play in the profitability of organisations. Thus defensive advertising is incorporated into the Lanchester model. Martín-Herrán et al. (2012) and Jørgensen and Sigué (2015) considered how advertising efforts directed at an organisation's own clients can reduce the implications of the competitors' offensive strategies. Erickson (1993) included defensive advertising in the Lanchester model. He analysed the ratio of offensive to defensive advertising and assumed that an increase in this ratio increases the organisation's market share.

The classic Lanchester models suffer from the unrealistic assumption that, without any advertising efforts, the market share of each player remains constant. Wang and Wu (2001) and Prasad et al. (2012) improved upon this approach by including the decay rate in the model.

Existing analyses of the Lanchester model assume that the advertising decision is made for an infinite horizon; however this approach is not consistent with the standard observation that the product life cycle is finite (see Kotler \& Armstrong, 2017). In the work of Wang and Wu (2001) and Jørgensen and Sigué (2015), this assumption is relaxed and time-varying model parameters are taken into consideration, whereas an infinite horizon concept limits the analysis to the stationary solution in which the model parameters are constant. Therefore the finite horizon idea represents a more effective tool by which managers can evaluate advertising strategies across a short horizon.

\section{The Vidale-Wolfe models}

The second group of models contains those derived from the monopolistic model proposed by Vidale and Wolfe (1957). Here it is assumed that rate of cumulative sales increases in response to offensive advertising that focuses on the potential customers that belong to an untapped market and without any advertising efforts the cumulative sales decline. Finally the competitor's advertising efforts do not reduce sales. These models were analysed by Deal (1979), Erickson (1995), Erickson (2009), and Grosset and Viscolani (2015).

\section{The Leitmann and Schmitendorf models}

Some models combine the Lanchester and Vidale and Wolfe (1957) approaches. The main difference that such approaches offer is that they operate on the understanding that the advertising activities are directed at all customers within the market. The same type of advertising actions are directed at the customers 
of rival organisations with the intention of attracting new customers as those that are employed to retain customers. From the discussion presented in Section 0 it can be established that this assumption is unrealistic. The model includes the decay rate (Leitmann \& Schmitendorf, 1978; Feichtinger, 1983; Dragone, Lambertini, \& Palestini, 2010).

\section{The Goodwill models}

The last group of models is based on the idea proposed by Nerlove and Arrow (1962). In this category of models the evolution of each company's goodwill depends positively on its own advertising efforts and negatively on the competitor's advertising strategies (Nair \& Narasimhan, 2006; Amrouche, Martín-Herrán, \& Zaccour, 2008; Viscolani \& Zaccour, 2009). It is assumed that, in the absence of advertising efforts, goodwill decreases over time. Moreover all authors consider only one type of advertising effort that is targeted at the entire market. A concise summary of the literature on goodwill modelling was recently presented by Crettez, Hayek and Zaccour (2018).

\section{The methodology of the new Lanchester model}

The assumption is that two competitive companies operate in a growing market for durable products. The model may be applied to $a$ product for which an offensive advertising is neutralized by the competitor's defensive strategies. We assume that both players make strategic decisions regarding the finite horizon $(T<\infty)$. In contradiction to most of the literature (see Jørgensen and Zaccour, 2012 , for reviews) a growing market is considered. At the beginning $S_{i}(t)$ denotes the rate of sale of company $i$ at time $t \in[0, T]$, and $M$ the saturation level of the market. Then based on Fruchter (1999) it is assumed that

$$
M=S_{i}(t)+S_{3-i}(t)+\tilde{\varepsilon}(t), \quad t \in[0, T], \quad i=1,2,
$$

where $\tilde{\varepsilon}(t)$ is the potential market in time $t$. Thus the potential market is the difference between the saturation of the market and the total current rate of sales of both companies. Dividing equation (1) by the level of market saturation $M$, we obtain

$$
1=x_{i}(t)+x_{3-i}(t)+\varepsilon(t), \quad i=1,2,
$$

where $x_{i}(t)=\frac{S_{i}(t)}{M}$ expresses the fraction of the competitor's sales relative to the saturation level of the market, or the market share of player $i$. Moreover 
$\varepsilon(t)=\frac{\tilde{\varepsilon}(t)}{M}$ describes the rate of the potential market. In the model it is assumed that the potential market contains new customers and customers who are dissatisfied with the usage of the current product. Note, if $\varepsilon(t)=0$ a mature market is the result.

\subsection{The dynamics of market share}

The Lanchester model is modified by taking into account several new factors that are relevant for the economic description of the competition.

First it is assumed that different types of advertising efforts influence the market share. The competitor, $i$, uses offensive advertising to acquire rivals' customers and to attract customers from the potential market; thus the rate of offensive advertising activities, $O M_{i}(t)$, touch the parts of the market that do not belong to company $i$ (similar to the assumption made in Fruchter (1999)). Besides the same firm also applies defensive advertising to neutralise the offensive action of a rival and, therefore, it retains the company's own customers. Hence the rate of defensive advertising activities, $D M_{i}(t)$, affect their own part of the market. Both advertising strategies change in time $t$, where $t \in[0, T]$. Moreover the modified model includes the heterogeneous decay rate of the market share for player in time $t, \delta_{i}(t)$. Thus the dynamics of the market share of competitor is governed by the following modified Lanchester model

$$
\left\{\begin{aligned}
\dot{x}_{i}(t)= & -\delta_{i}(t) x_{i}(t)+\left[o_{i}(t)\left(1-x_{i}(t)\right) O M_{i}(t)+d_{i}(t) x_{i}(t) D M_{i}(t)\right]+ \\
& -\left[o_{3-i}(t)\left(1-x_{3-i}(t)\right) O M_{3-i}(t)+d_{3-i}(t) x_{3-i}(t) D M_{3-i}(t)\right], \quad t \in[0, T] \\
x_{i}(0)= & x_{i, 0}, \quad i=1,2
\end{aligned}\right.
$$

In equations (3), $o_{i}(t)$ and $d_{i}(t)$ stand for the effectiveness of the offensive and defensive advertising activities, respectively in time $t$. The initial market share of player $i$ is indicated by $x_{i, 0}$.

In this equation it is assumed that the market share of the two competitors change continually over time. The dynamics of market share of th company depends positively on its defensive and offensive advertising efforts (first square bracket). The second square bracket signifies a decline in $x_{i}$ as result of both rivals' advertising activities. The approach described by Erickson (1993) is adopted and it is assumed that all of the company's customers are exposed to the competitor's advertising activities and, hence, they should be protected against them.

Remark 1: Note that, without any advertising efforts, i.e. $D M_{i}(t)=0$ and $O M_{i}(t)=0$ for $t \in[0, T]$, the market share of both companies declines independently with decay rate $\delta_{t}(t)$. This observation could not be obtained in the 
previous studies. Previous models analysed in the literature assumed that the market share remains unchanged without advertising efforts which is far from the observation of the real market behaviours.

Under the assumption given in equation (2) the result is $1-x_{i}(t)=x_{3-i}(t)+$ $+\varepsilon(t)$ for $i=1,2$ and for each $t \in[0, T]$. Thus the modified Lanchester model (3) can be reformulated to:

$$
\left\{\begin{aligned}
\dot{x}_{i}(t)= & -\delta_{i}(t) x_{i}(t)+x_{i}(t)\left[d_{i}(t) D M_{i}(t)-o_{3-i}(t) O M_{3-i}(t)\right]+ \\
& +x_{3-i}(t)\left[o_{i}(t) O M_{i}(t)-d_{3-i}(t) D M_{3-i}(t)\right]+ \\
& +\mathcal{E}(t)\left[o_{i}(t) O M_{i}(t)-o_{3-i}(t) O M_{3-i}(t)\right] \\
& x_{i}(0)=x_{i 0}, \quad i=1,2
\end{aligned}\right.
$$

for $t \in[0, T]$.

From equation (4) it can be observed that the defensive advertising activities of company $i$ are weakened by the competitor's offensive efforts and the churn rate (the second component of the equation). Moreover the offensive actions of company $i$ are weakened by the competitive defensive strategies (the third component). We also note that only offensive strategies compete on the market potential (the last component).

\subsection{The dynamics of the potential market}

Taking the derivative of (2) with respect to time $t$ and making use of (3) a linear ODE for $t \in[0, T]$ is obtained

$$
\begin{aligned}
\dot{\varepsilon}(t)=-\dot{x}_{i}(t)-\dot{x}_{3-i}(t)=\delta_{i}(t) x_{i}(t)+\delta_{3-i}(t) & x_{3-i}(t)= \\
& =\delta_{i}(t)\left(1-x_{3-i}(t)-\varepsilon(t)\right)+\delta_{3-i}(t) x_{3-i}(t) .
\end{aligned}
$$

For the given initial condition, the following equation is relevant

$$
\varepsilon(t)=\varepsilon(0) \mathrm{e}^{-\Delta_{1}(t)}+\mathrm{e}^{\Delta_{1}(t)} \int_{0}^{t} \mathrm{e}^{-\Delta_{1}(s)}\left(\delta_{1}(s)+\left(\delta_{2}(s)-\delta_{1}(s)\right) x_{2}(s)\right) d s
$$

for $\Delta_{i}(t)=\int_{0}^{t} \delta_{i}(s) d s$. Since $\varepsilon(t)$ represents the rate of potential market at time $t$, equation (5) demonstrates that the rate of the potential market depends on the initial level of the rate of potential market and on the cumulative rate of one of the competitor's market share and on both competitors' decay rates. In the Lanchester model, without the defensive efforts proposed by Fruchter (1999), the potential market depends on the cumulative advertising efforts of all the players. Therefore, when all defensive activities are included does not depend on any advertising efforts. This suggests that competitive defensive and offensive activities neutralize each other during the process of generating new customers in the untapped part of the market. Moreover, if assumed that 
$\delta_{1}=\delta_{2}=\delta$, then the formula (5) may be simplified to $\varepsilon(t)=1-(1-\varepsilon(0)) e^{-\delta t}$. Since $\frac{\partial \varepsilon}{\partial \delta}=\delta(1-\varepsilon(0)) e^{-\delta t} \geq 0$ the authors claim that the growth of decay rate causes an increase in potential market when rates of depreciation are the same for both companies.

\subsection{Objectives of competing companies}

Given the hypothesis related to decreasing marginal return of advertising activities (see Bagwell, 2007), it is assumed that the instantaneous costs of defensive and offensive advertising activities are given by $C\left(O M_{i}\right)=\frac{\beta_{i}}{2} O M_{i}^{2}$, $C\left(D M_{i}\right)=\frac{\beta_{i}}{2} D M_{i}^{2}, \quad i=1,2$ where $\frac{\beta_{i}}{2}$ is the unit cost of advertising activities. Both players aim to achieve the best allocation of advertising efforts across defensive and offensive advertising in order to maximise the sum of profit over the finite decision horizon $T$. Hence the goal functional for the each company takes the form

$$
\begin{aligned}
J_{i}\left(O M_{i}, D M_{i}, O M_{3-i}, D M_{3-i}\right) & = \\
& =\int_{0}^{T}\left(\Pi_{i} x_{i}(t)-\frac{\beta_{i}}{2}\left(O M_{i}^{2}(t)+D M_{i}^{2}(t)\right)\right) d t, \quad i=1,2,
\end{aligned}
$$

where $\Pi_{i}$ is the constant unit profit margin for each company and $x_{i}$ is the solution of (3). Similarly to Wang and Wu (2001), Bass, Krishnamoorthy, Prasad, and Sethi (2005), and Jørgensen and Sigué (2015) the assumption is that the decision horizon is reasonably short and it is possible to omit discounting of future profits.

The vector of controls is denoted by $\mathbf{u}_{i}=\left(O M_{i}, D M_{i}\right)$ and the vector of states $\mathbf{x}=\left(x_{1}, x_{2}\right)$. In conclusion the competitive companies face the differential game in the form of

$$
\max _{\mathbf{u}_{i}} J_{i}\left(\mathbf{u}_{i}, \mathbf{u}_{3-i}\right) \text { subject to equation (3). }
$$

\section{The Markovian Nash equilibrium}

The differential game (7) is now considered in which it is found that the current value Hamiltonian for player $i$ is defined by as per the approach suggested by Kamien and Schwartz (2012):

$$
H_{i}\left(\mathbf{x}, \mathbf{u}_{i}, \mathbf{u}_{3-i}, \lambda_{i j}, \lambda_{i, 3-j}\right)=J_{i}\left(\mathbf{u}_{i}, \mathbf{u}_{3-i}\right)+\lambda_{i j} \dot{x}_{j}+\lambda_{i, 3-j} \dot{x}_{3-j},
$$


where $\lambda_{i j}$ is the adjoint variable for $i, j=1,2$. Observe that the Hamiltonians (8) consist of current and future return. The adjoint variables measure the effect of future return of a unit change in the state variables. Thus, $\lambda_{i j}(t)$ is the change in return to competitor $i$ from time $t$ to the horizon $T$ with respect to a unit change of market share $x_{i}$. Furthermore both components of Hamiltonian depend on advertising efforts: current return through current cost of advertising actions and future return through advertising efforts affecting $\dot{x}_{i}$ and thereby affecting future cash flows (Erickson, 1985). Based on the necessary optimality conditions it is obtained that the offensive and defensive Nash equilibrium for player $i$ at time $t$ take the following forms

$O M_{i}^{*}(t)=\frac{o_{i}(t)\left(1-x_{i}(t)\right)\left(\lambda_{i i}(t)-\lambda_{i, 3-i}(t)\right)}{\beta_{i}}, D M_{i}^{*}(t)=\frac{d_{i}(t) x_{i}(t)\left(\lambda_{i i}(t)-\lambda_{i, 3-i}(t)\right)}{\beta_{i}}$

for $t \in[0, T], i=1,2$. Next, the system of ordinary differential equations for the adjoint variables is obtained as follows:

$$
\left\{\begin{aligned}
\dot{\lambda}_{i i}(t)= & -\prod_{i}+\lambda_{i i}(t)\left(\delta_{i}(t)+o_{i}(t) O M_{i}^{*}(t)-d_{i}(t) D M_{i}^{*}(t)\right)+ \\
& +\lambda_{i, 3-i}(t)\left(d_{i}(t) D M_{i}^{*}(t)-o_{i}(t) O M_{i}^{*}(t)\right) \\
\dot{\lambda}_{i, 3-i}(t)= & \lambda_{i i}(t)\left(d_{3-i}(t) D M_{3-i}^{*}(t)-o_{3-i}(t) O M_{3-i}^{*}(t)\right)+ \\
& +\lambda_{i, 3-i}(t)\left(\delta_{3-i}(t)+o_{3-i}(t) O M_{3-i}^{*}(t)-d_{3-i}(t) D M_{3-i}^{*}(t)\right)+ \\
& +\frac{1}{\beta_{3-i}(t)}\left(\lambda_{i, 3-i}(t)-\lambda_{i, i}(t)\right)\left(\lambda_{3-i, i}(t)-\lambda_{3-i, 3-i}(t)\right) \times \\
& \times\left[o_{3-i}^{2}(t)\left(1-x_{3-i}(t)\right)-d_{3-i}^{2}(t) x_{3-i}(t)\right] \\
\lambda_{i i}(T)=0, \quad & \lambda_{i, 3-i}(T)=0, \quad i=1,2
\end{aligned}\right.
$$

for $O M_{i}^{*}, D M_{i}^{*}$ given by (9). In the literature system of differential equations (10) with (3) is known as the boundary value problem and usually does not possess an analytical solution. An analysis of the ratio of both type of optimal advertising strategies given by (9); i.e. $\frac{O M_{i}^{*}(t)}{D M_{i}^{*}(t)}=\frac{o_{i}(t)\left(1-x_{i}(t)\right)}{d_{i}(t) x_{i}(t)}, t \in[0, T], i=1,2$ is analysed. The following claim is made:

Observation 1: The optimal defensive advertising strategies outperform optimal offensive strategies as the market share increases. Indeed, for a fixed $t \in[0, T]$ $\frac{\partial}{\partial x_{i}}\left(\frac{O M_{i}^{*}}{D M_{i}^{*}}\right)=-\frac{o_{i}(t)}{d_{i}(t) x_{i}^{2}(t)}<0$ is obtained. This observation is consistent with many previous findings about the relationship between offensive and defensive strategies for a firm with a strong or weak position on the market. 
Observation 2: The level of $x_{i}$ for which optimal defensive advertising starts to exceed optimal offensive strategy depends on the effectiveness of both types of advertising. More precisely it is assumed that $o_{i}(t)=k \cdot d_{i}(t)$. For $k \in(0,1)$, the offensive strategy is more effective than defensive, for $k>1$ the reverse dependence can be seen. Then, $\frac{O M^{\star}}{D M^{*}}>1$ if $x_{i}<\frac{k}{k+1}$. Thus the more efficient the offensive strategy is, the higher the defensive strategies for the higher levels of market share. For the same effectiveness (i.e., $k=1$ ), the defensive strategy becomes higher level for $x_{i}=0.5$.

Observation 3: Since $\frac{\partial x_{i}}{\partial \delta_{i}}<0$, it is observed that the growth of the decay rate $\delta_{i}$ increases the share of the offensive to the defensive advertising strategy. Indeed, $\frac{\partial}{\partial \delta_{i}}\left(\frac{O M^{*}}{D M^{*}}\right)=-\frac{o_{i}}{d_{i} x_{i}^{2}} \cdot \frac{\partial x_{i}}{\partial \delta_{i}}>0$. The high level of the decay rate entails that many customers leave the company for the potential market. Therefore it is optimal to increase offensive advertising strategies that target this segment of the market.

\section{Sensitivity of the modified Lanchester model}

A numerical method to solve the system with (3) is used to fully understand and better evaluate the way in which some essential model parameters influence companies' advertising strategies. Specifically an initial market share in combination with variations in the decay rate has an impact on optimal advertising strategies is investigated and the market share during the decision horizon and how this ultimately affects company performance. Moreover the results obtained from a growing market with that of a mature market are compared.

In simulations it is assumed that any model parameters have the same value for both companies, except the initial market share and the attrition rate. Thus based on the estimation offered by Erickson (2009) it can be stated that the decision horizon $T=1$, the unit cost of advertising $\beta_{i}=0.01$, and the effectiveness of advertising efforts is the same for defensive and offensive strategies, ie. $o_{i}=$ $d_{i}=0.07$ and the constant unit profit margin $\Pi_{i}=1.2$. According to Kotler and Amstrong (2017), in a competitive market, there is a market leader and market challengers. They define the market leader (denoted as $C_{2}$ ) as the firm with the largest market share in a given market and a market challenger $\left(C_{1}\right)$ that is fighting to increase its market share. In situations such as this, when the initial market share is the same for companies, we refer to the market as symmetric.

The solutions of the new model for all combinations of $x_{i, 0} \in\{0.1, \ldots, 0.9\}$, such that $x_{1,0}+x_{2,0} \leq 1$ and for each $\delta_{i} \in\{0,0.1, \ldots, 0.9\}$ with $i=1,2$ are examined and the new model for time-varying decay rate is inspected. The increasing decay rate, $\delta_{i}(t) \uparrow$, given by $\delta_{i}(t)=0.96 t+0.02$, and the decreasing churn, 
$\delta_{i} \downarrow$, given by $\delta_{i}(t)=-0.96 t+0.98$ are considered. In the next part of this section we present only selected results that allow an evaluation of the validity of the research hypotheses presented in Section 2.

The influence of the potential market on optimal advertising strategies In the first case two scenarios in which the strength of the leader is changed should be considered where the challenger has the same initial market share, equal to 0.2 . In the first scenario (S1) the leader starts the game at 0.3 . In the second (S2), the leader starts at 0.8 . In both scenarios the challenger may acquire the same part of the market. However in the first case there is a large potential market, while in the second the mature market is analysed. The leader's attrition rate does not change and is equal to 0.1 , while for the challenger $\delta_{1} \in\{0,0.5,0.9\}$ is obtained. How the size of the potential market affects the challenger's optimal advertising strategies and profit is examined. The results are presented in Table 1.

Table 1. The influence of the potential market on the challenger's optimal advertising strategies and profit

\begin{tabular}{|c|c|c|c|c|c|c|c|c|}
\hline & \multicolumn{4}{|c|}{$S 1: x_{2,0}=0.3$} & \multicolumn{4}{|c|}{ S2: $x_{2,0}=0.8$} \\
\hline & $\begin{array}{c}\text { mean } \\
D M_{1}^{\star}\end{array}$ & $\begin{array}{c}\text { mean } \\
O M_{1}^{\star}\end{array}$ & mean $x_{1}^{\star}$ & $J_{1}$ & $\begin{array}{c}\text { mean } \\
D M_{1}^{\star}\end{array}$ & $\begin{array}{c}\text { mean } \\
O M_{1}^{*}\end{array}$ & mean $x_{1}^{*}$ & $J_{1}$ \\
\hline$\delta_{1}=0$ & 0.945 & 3.533 & 0.214 & 0.187 & 1.251 & 4.494 & 0.222 & 0.166 \\
\hline$\delta_{1}=0.5$ & 0.593 & 2.895 & 0.161 & 0.136 & 0.860 & 3.974 & 0.167 & 0.113 \\
\hline$\delta_{1}=0.9$ & 0.435 & 2.603 & 0.129 & 0.107 & 0.643 & 3.555 & 0.135 & 0.084 \\
\hline
\end{tabular}

It is recognised that in the mature market (S2) the challenger is forced to invest more heavily in offensive advertising than it would when operating in a growing market. Similar results have been obtained for defensive advertising; however, the differences are not as significant. Thus the hypothesis $\mathrm{H}_{3}$ that the existence of the potential market allows the challenger to invest less in advertising is confirmed. Large advertising efforts in the mature market mean that the average market share of player $C_{1}$ is slightly larger. The costs associated with increased advertising efforts result in lower profits than those generated in the growing market. This means that hypothesis $\mathrm{H}_{1}$ is also confirmed. From Table 1 it is recognized that the increase in the churn rate decreases the challenger's profit in the growing and mature market which supports hypothesis $\mathrm{H}_{2}$.

\section{The time-varying attrition rate}

In this case how the time-varying churn rate affects the optimal advertising strategies and the company profit is analysed. Four simulations are consid- 
ered in which $\delta_{i}$ is an increasing or decreasing function over time and the results are compared with the simulation results for a constant churn, $\delta_{i} c$. In all experiments the mean value of $\delta_{i}$ is equal to 0.5 . The results are presented in Figure 1-Figure 3.
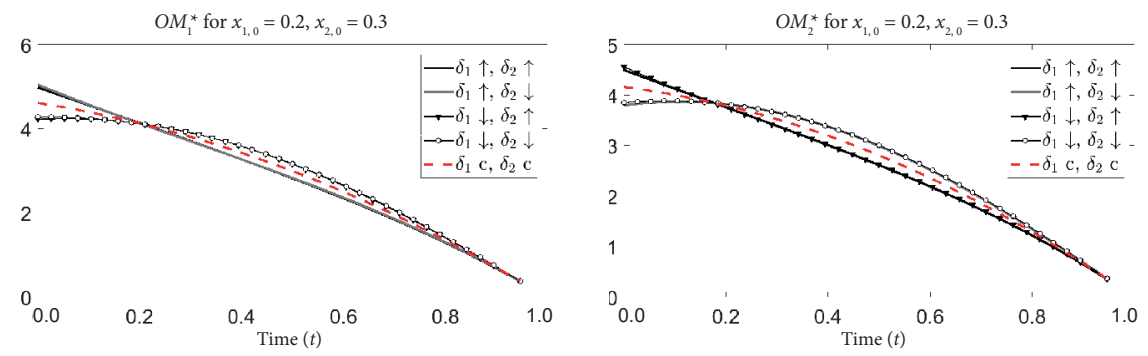

Figure 1. The optimal offensive advertising strategies in an experiment with the time-varying churn rate

For both players the variation in time of $\delta_{i}$ has a strong influence on the offensive strategies. At the beginning of decision horizon, the increasing $\delta_{i}$ exhibits significantly higher values in comparison to the decreasing and constant $\delta_{i}$.

As time goes by the level of increasing decay rate is higher than the decreasing rate. Therefore the inverse relationship between advertising strategies for increasing and decreasing rates can be observed. Thus hypothesis $\mathrm{H}_{6}$ is rejected because the offensive efforts for increasing decay are not always greater than offensive efforts for a declining rate. This observation is the same for both players.
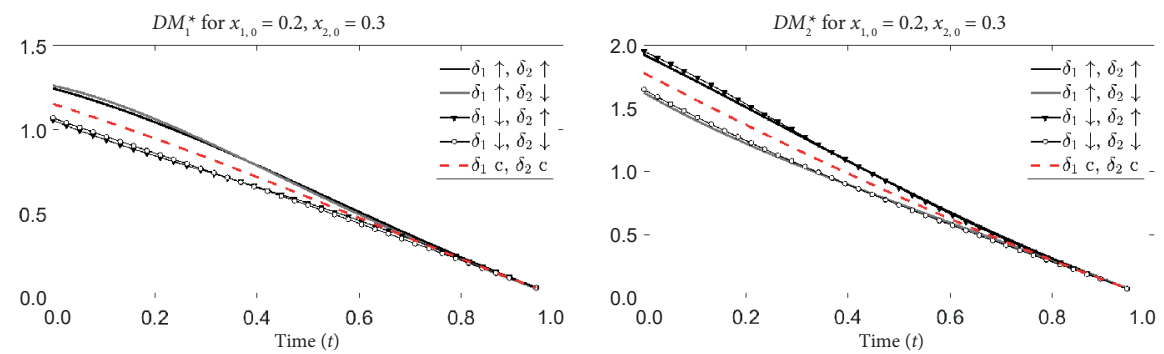

Figure 2. The optimal defensive advertising strategies in an experiment with the time-varying churn rate

The defensive strategies for the increasing attrition rate exceed the strategies for the decreasing and constant rate. Therefore hypothesis $\mathrm{H}_{8}$ is confirmed in that a_declining attrition rate generates the lowest optimal defensive strategies. This observation is also the same for both players. 

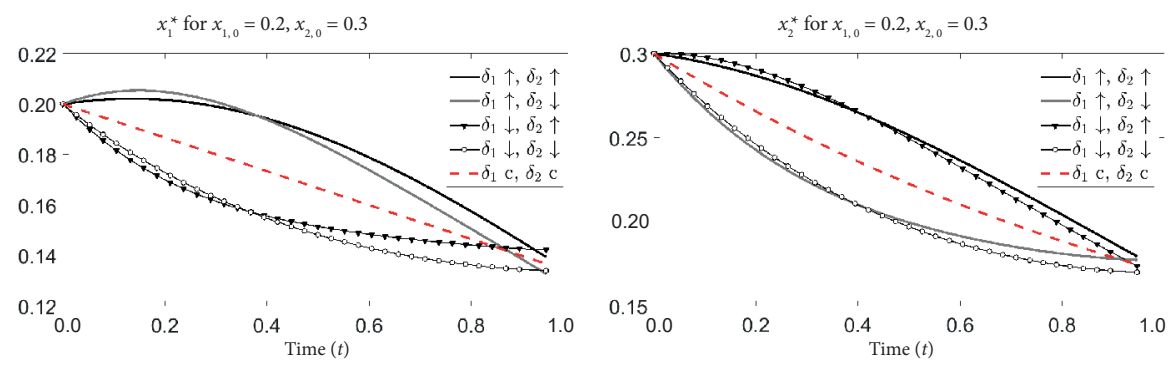

Figure 3. The market share associated with optimal advertising strategies in an experiment with the time-varying churn rate

Moreover the strong influence in the decision horizon of the different shape of attrition rates on the market share (see Figure 3) can be seen. For the rising churn rate the market share associated with optimal advertising significantly exceeds the optimal market share for the constant decay rate. The optimal market share for the declining attrition rate is smaller than $x_{i}$ for the constant decay rate.

Finally the profit for the time-varying attrition rate is compared. Table 2 presents the percentage changes of profit with respect to the simulation in which the attrition rate is constant.

Table 2. The profit of each competitor in the growing market for $x_{1,0}=0.2, x_{2,0}=0.3$. Percentage changes for each player are determined relative to the profit obtained for a constant churn rate

\begin{tabular}{|c|c|c|c|c|}
\hline & $\delta_{1} \uparrow, \delta_{2} \uparrow$ & $\delta_{1} \uparrow, \delta_{2} \uparrow$ & $\delta_{1} \downarrow, \delta_{2} \downarrow$ & $\delta_{1} \downarrow, \delta_{2} \downarrow$ \\
\hline$J_{1}$ & $11,38 \%$ & $9,75 \%$ & $-7,55 \%$ & $-10,21 \%$ \\
\hline$J_{2}$ & $10,73 \%$ & $-8,25 \%$ & $10,01 \%$ & $-9,65 \%$ \\
\hline
\end{tabular}

The results highlight that it is more profitable for the company to have very low attrition rate at the beginning of the decision horizon, which increases as time goes by, than a decreasing churn rate. The profit may increase by up to $10 \%$ compared to the constant churn rate. Similar observations are obtained for the mature market. Thus hypothesis $\mathrm{H}_{4}$ is rejected.

The influence of the churn rate on offensive advertising Figure 4 presents the optimal offensive advertising. The first scenario involves symmetric companies that have an initial market share equal to 0.1 . In the second scenario the initial market share for the challenger is equal to 0.4 , for the leader $x_{2,0}$, it is equal to 0.5 . 

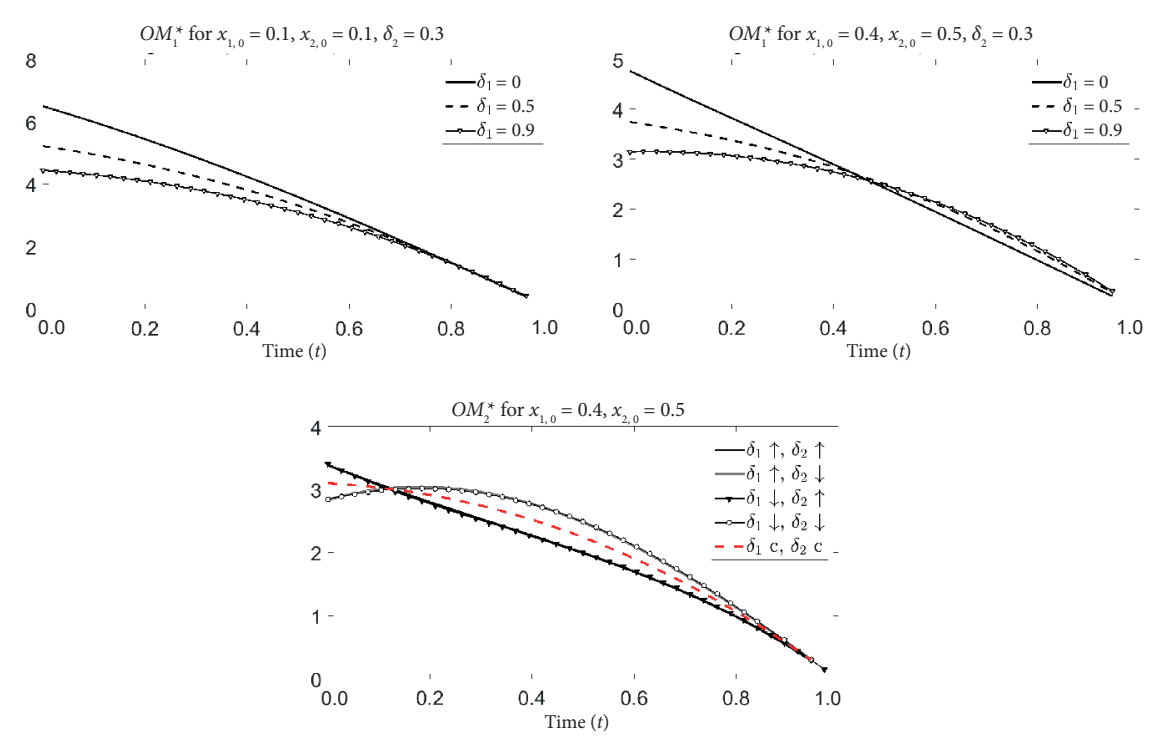

Figure 4. The challenger's and the leader's optimal offensive advertising strategies: $O M_{i}^{*}$

The results from the symmetric market confirm that the offensive strategies decrease as the attrition rate increases. However it is not a rule as was proposed in hypothesis $\mathrm{H}_{5}$. In the second scenario it is optimal to increase the offensive strategy for a higher attrition rate. Thus hypothesis $\mathrm{H}_{5}$ is rejected.

The influence of the churn rate on defensive advertising

Figure 5 presents the optimal defensive advertising strategies for the leader and the challenger. The initial market shares are equal to 0.1 and 0.2 , respectively. These numerical experiments confirm hypothesis $\mathrm{H}_{7}$. In each experiment the growth of the attrition rate declines the optimal defensive advertising strategy.
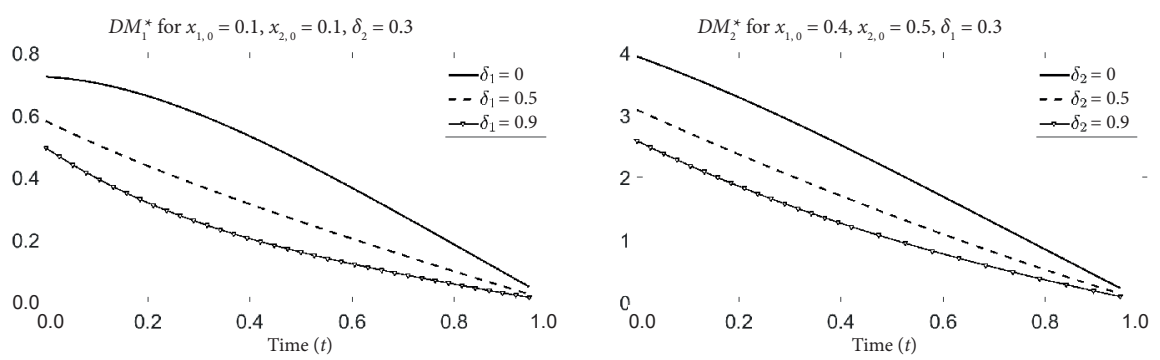

Figure 5. The challenger's and the leader's optimal defensive advertising strategies, $D M_{i}^{*}$ 


\section{Conclusions}

This paper aimed to develop a comprehensive decision-making framework that allows advertising managers to optimally allocate their resources between offensive and defensive advertising in a competitive, growing market. The research employed the differential game-based approach on the modified Lanchester model. A Markovian Nash equilibrium for offensive and defensive advertising effort design over a finite decision horizon was determined.

For the first time in the literature it was possible to observe the importance of taking the time-varying decay rate into consideration. In the experiments significant differences in advertising efforts and market share when the churn rate depended on time were observed. There was an examination as to which strategies-decreasing or increasing churn rate-were more profitable for the company. It was found that, contrary to expectations, the company may generate a more substantial profit of up to $10 \%$ higher when the decay rate is increasing over time.

The analysis of the influence of the decay rate presented in this paper reveals that the growth of the decay rate decreases defensive advertising. These surprising results were obtained for the offensive strategies. One may expect that, since the growth of the decay rate increases the potential market, offensive advertising should increase. However, from the definition of the decay rate, it may be concluded that the high level of is the result of the existence of a large group of disloyal consumers. Therefore the heavy investment in advertising that targets new consumers is not always optimal.

The potential market has a substantial impact on advertising efforts. When the potential market is very low, and the decay rate is high, it is optimal to increase advertising efforts. When the potential market is large, an increase in the attrition rate reduces offensive advertising. In all cases the growth of the decay rate decreases the profit.

In future research, it would be interesting to consider generic advertising similar to the work conducted by Jørgensen and Sigué (2015). An analysis of the influence of the depreciated rate on the advertising strategies could shed new light on the process by which business managers should develop longterm marketing strategies.

\section{References}

Agarwal, R., \& Bayus, B. L. (2002). The market evolution and take-off of product innovations. SSRN Electronic Journal, 48(8), 1024-1041.

Ahn, J. H., Han, S. P., \& Lee, Y. S. (2006). Customer churn analysis: churn determinants and mediation effects of partial defection in the Korean mobile telecommunications service industry. Telecommunications Policy, 30(10-11), 552-568. 
Amrouche, N., Martín-Herrán, G., \& Zaccour, G. (2008). Pricing and advertising of private and national brands in a dynamic marketing channel. Journal of Optimization Theory and Applications, 137(3), 465-483.

Bagwell, K. (2007). The economic analysis of advertising. Handbook of Industrial Organization, 3, 1701-1844.

Bass, F. M., Krishnamoorthy, A., Prasad, A., \& Sethi, S. P. (2005a). Advertising competition with market expansion for finite horizon firms. Journal of Industrial and Management Optimization, 1(1), 1-19.

Chandy, R. K., Tellis, G. J., MacInnis, D. J., \& Thaivanich, P. (2001). What to say when: advertising appeals in evolving markets. Journal of Marketing Research, 38(4), 399-414.

Chintagunta, P. K., \& Vilcassim, N. J. (1992). An empirical investigation of advertising strategies in a dynamic duopoly. Management Science, 38(9), 1230-1244.

Crettez, B., Hayek, N., \& Zaccour, G.. (2018). Existence and uniqueness of optimal dynamic pricing and advertising controls without concavity. Operations Research Letters, 46(2), 199-204.

Davidson, H., \& Keegan, W. J. (2004). Offensive marketing, Elsevier, Amsterdam.

Deal, K. R. (1979). Optimizing advertising expenditures in a dynamic duopoly. Operations Research, 27(4), 682-692.

Dekimpe, M. G., \& Hanssens, D. M. (1995). The persistence of marketing effects on sales. Marketing Science, 14(1), 1-21.

Dragone, D., Lambertini, L. \& Palestini, A. (2010). The Leitmann-Schmitendorf advertising game with $\mathrm{n}$ players and time discounting. Applied Mathematics and Computation, 217(3), 1010-1016.

Erickson, G. M. (1985). A model of advertising competition. Journal of Advertising Research, 22(3), 297-304.

Erickson, G. M. (1992). Empirical analysis of closed-loop duopoly advertising strategies. Management Science, 38(12), 1732-1749.

Erickson, G. M. (1993). Offensive and defensive advertising: closed-loop duopoly strategies. Advertising Letters, 4(4), 285-295.

Erickson, G. M. (1995). Advertising strategies in a dynamic oligopoly. Journal of Marketing Research, 32(2), 233-237.

Erickson, G. M. (2009). An oligopoly model of dynamic advertising competition. European Journal of Operational Research, 197(1), 374-388.

Feichtinger, G. (1983). The Nash solution of an advertising differential game: generalization of a model by Leitmann and Schmitendorf. IEEE Transactions on Automatic Control, 28(11), 1044-1048.

Fruchter, G. E. (1999). Short communications-oligopoly advertising strategies with market expansion. Optimal Control Applications and Methods, 20(4), 199-212.

Fruchter, G. E., \& Kalish, S. (1997). Closed-loop advertising strategies in a duopoly. Management Science, 43(1), 54-63.

Grosset, L., \& Viscolani, B. (2015). Open-loop Nash equilibrium in Erickson's oligopoly model. Nonlinear Analysis and Differential Equations, 3(4), 167-172.

Hamilton, R. W., Rust, R. T., \& Dev, C. S. (2017). Which features increase customer retention?. MIT Sloan Management Review, 58(2), 79-84. 
Hogan, J. E., Lemon, K. N., \& Libai, B. (2003). What is the true value of a lost customer?. Journal of Service Research, 5(3), 196-208.

Jarrar, R., Martín-Herrán, G., \& Zaccour, G. (2004). Markov perfect equilibrium advertising strategies of Lanchester duopoly model: a technical note. Management Science, 50(7), 995-1000.

Jørgensen, S., \& Sigué, S.-P. (2015). Defensive, offensive, and generic advertising in a Lanchester model with market growth. Dynamic Games and Applications, 5(4), 523-539.

Jørgensen, S., \& Zaccour, G. (2012). Differential games in advertising. New York: Springer Science \& Business Media.

Kamien, M. I., \& Schwartz, N. L. (2012). Dynamic optimization: the calculus of variations and optimal control in economics and management. New York: Dover Publications, Inc.

KhakAbi, S., Gholamian, M. R., \& Namvar, M.. (2010). Data mining applications in customer churn management. ISMS 2010 - UKSim/AMSS 1st International Conference on Intelligent Systems, Modelling and Simulation, 220-225.

Kotler, P., \& Armstrong, G. (2017). Principles of Marketing, New York: Pearson Education.

Leitmann, G., \& Schmitendorf, W. E. (1978). Profit maximization through advertising: a nonzero sum differential game approach. IEEE Transactions on Automatic Control, 23(4), 645-650.

Libai, B., Muller, E. \& Peres, R. (2009). The diffusion of services. Journal of Marketing Research, 46(2), 163-175.

Martín-Herrán, G., McQuitty, S., \& Sigué, S.P. (2012). Offensive versus defensive advertising: what is the optimal spending allocation?. International Journal of Research in Advertising, 29(2), 210-219.

Min, S., Zhang, X., Kim, N., \& Srivastava, R. K. (2016). Customer acquisition and retention spending: an analytical model and empirical investigation in wireless telecommunications markets. Journal of Advertising Research, 53(5), 728-744.

Nair, A., \& Narasimhan, R. (2006). Dynamics of competing with quality- and advertising-based goodwill. European Journal of Operational Research, 175(1), 462-474.

Nerlove, M., \& Arrow, K. J. (1962). Optimal advertising policy under dynamic conditions. Economica, 29(114), 129-142.

Neslin, S. A., Gupta, S., Kamakura, W., Lu, J., \& Mason, C. H. (2006). Defection detection: measuring and understanding the predictive accuracy of customer churn models. Journal of Marketing Research, 43(2), 204-211.

Nguyen, D., \& Shi, L. (2006). Competitive advertising strategies and market-size dynamics: a research note on theory and evidence. Management Science, 52(6), 965-973.

Prasad, A., Sethi, S. P., \& Naik, P. A. (2012). Understanding the impact of churn in dynamic oligopoly markets. Automatica, 48(11), 2882-2887.

Reichheld, F. F., \& Sasser, W. E. (1990). Zero defections: quality comes to services. Harvard Business Review, 68(5), 105-111.

Reinartz, W. J., \& Venkatesan, R. (2008). Decision models for customer relationship management (CRM). In B. Wierenga (Ed.), Handbook of Marketing Decision Models (pp. 291-326). Boston, MA: Springer. 
Rust, R.T., \& Chung, T.S. (2006). Marketing models of service and relationship. Marketing Science, 25(6), 560-580.

Rust, R. T., Lemon, K. N., \& Zeithaml, V. A. (2004). Return on marketing: using customer equity to focus marketing strategy. Journal of Marketing, 68(1), 109-127.

Vidale, M. L., \& Wolfe, H. B. (1957). An operations-research study of sales response to advertising. Operations Research, 5(3), 370-381.

Viscolani, B., \& Zaccour, G. (2009). Advertising strategies in a differential game with negative competitor's interference. Journal of Optimization Theory and Applications, 140(1), 153-170.

Wang, Q., \& Wu, Z. (2001). A duopolistic model of dynamic competitive advertising. European Journal of Operational Research, 128(1), 213-226. 